\title{
Interstage attrition between bidirectional Glenn and Fontan palliation in children with hypoplastic left heart syndrome
}

\author{
Waldemar F. Carlo, MD, ${ }^{a}$ Kathleen E. Carberry, MPH, RN, ${ }^{\text {b }}$ Jeffrey S. Heinle, MD, ${ }^{\text {b, }}$ \\ David L. Morales, MD, ${ }^{\mathrm{b}, \mathrm{c}}$ E. Dean McKenzie, MD, ${ }^{\mathrm{b}, \mathrm{c}}$ Charles D. Fraser, Jr, MD, ${ }^{\mathrm{b}, \mathrm{c}}$ and \\ David P. Nelson, MD ${ }^{\mathrm{d}}$
}

\begin{abstract}
Objective: With improving operative mortality for staged palliation of hypoplastic left heart syndrome, interstage death accounts for an increasing proportion of hypoplastic left heart syndrome mortality. We investigated risk factors for death or cardiac transplantation during the interstage period between bidirectional Glenn and Fontan procedures in children with hypoplastic left heart syndrome.
\end{abstract}

\begin{abstract}
Methods: Patients with hypoplastic left heart syndrome who underwent bidirectional Glenn between August 1995 and June 2007 were screened. Standard risk patients, defined by having been discharged after both Norwood and bidirectional Glenn, were included for analysis. Patient demographic, echocardiographic, cardiac catheterization, and operative data were reviewed. Interstage attrition was defined as death or cardiac transplantation more than 30 days after bidirectional Glenn and before the Fontan procedure. Statistical analysis was carried out using the Student $t$ test, Pearson chi-square correlation, and Cox proportional hazard modeling for multivariable analysis.
\end{abstract}

Results: Ninety-two patients with hypoplastic left heart syndrome were alive at 30 days after bidirectional Glenn. Of these patients, 8 died and 3 underwent cardiac transplantation at a median of 391 days (range, 591175 days) after bidirectional Glenn, yielding an interstage attrition rate of $12 \%$. Removing the 7 patients who are still awaiting Fontan (but all of whom are at least 3.5 years after bidirectional Glenn) adjusts the attrition rate to $13 \%$. Interstage attrition did not correlate with hemodynamic data obtained at cardiac catheterization, aortic arch obstruction, or right ventricular dysfunction. Multivariable analysis demonstrated that the presence of moderate or severe tricuspid valve regurgitation (hazard ratio, 6.02; 95\% confidence interval, 1.56-23.24; $P<.01$ ) and weight $z$ score (hazard ratio, $0.38 ; 95 \%$ confidence interval, $0.16-0.88 ; P=.02$ ) were independent preoperative risk factors for interstage attrition.

Conclusions: Interstage attrition between bidirectional Glenn and Fontan procedures occurred in $12 \%$ of our study population. Moderate or greater tricuspid valve regurgitation and low weight $z$ score at the time of bidirectional Glenn are important risk factors for interstage attrition between the bidirectional Glenn and Fontan procedures in children with hypoplastic left heart syndrome. (J Thorac Cardiovasc Surg 2011;142:511-6)

Hypoplastic left heart syndrome (HLHS) accounts for more infant mortality than any other congenital heart disease in the United States. Furthermore, 5-year survival for HLHS ranges from $50 \%$ to $70 \%$ in multiple prior reports. ${ }^{1-7}$ With improving operative mortality for staged palliation of HLHS, interstage death accounts for an increasing proportion of the mortality. ${ }^{8}$ The incidence of interstage death between Norwood (stage I) and bidirectional Glenn (BDG,

\footnotetext{
From the Division of Pediatric Cardiology, ${ }^{\mathrm{a}}$ University of Alabama at Birmingham, Ala; Division of Congenital Heart Surgery, ${ }^{\mathrm{b}}$ Texas Children's Hospital, Houston, Tex; Division of Congenital Heart Surgery, ${ }^{\mathrm{c}}$ Baylor College of Medicine, Houston, Tex; and Division of Pediatric Cardiology, ${ }^{\mathrm{d}}$ Cincinnati Children's Hospital Medical Center, Ohio.

Disclosures: Authors have nothing to disclose with regard to commercial support. Received for publication June 29, 2010; revisions received Nov 24, 2010; accepted for publication Jan 19, 2011; available ahead of print June 27, 2011.

Address for reprints: Waldemar F. Carlo, MD, 176F STE 9100, 619 19th St S, Birmingham, AL 35249-6852 (E-mail: wfcarlo@peds.uab.edu). $0022-5223 / \$ 36.00$

Copyright (C) 2011 Published by Elsevier Inc. on behalf of The American Association for Thoracic Surgery

doi:10.1016/j.jtcvs.2011.01.030
}

stage II) palliation has been reported at $9 \%$ to $16 \%$, and risk factors for death during this period have been extensively investigated. ${ }^{1,2,6,9-12}$

The incidence of interstage attrition between BDG and Fontan (stage III palliation) ranges from $6 \%$ to $9 \%$ in studies with significant incomplete follow-up rates. ${ }^{6,9,13}$ Also, the risk factors for interstage attrition in this group have not been well delineated in the current era. The purpose of this study is to investigate risk factors for interstage attrition as defined by death or cardiac transplantation during the interstage period between BDG and Fontan palliation in children with HLHS.

\section{MATERIALS AND METHODS}

Patients with a diagnosis of HLHS who underwent Norwood stage I palliation at Texas Children's Hospital between August 1995 and June 2007 were screened. Other single ventricle anatomic variants were excluded, including right ventricular-dominant atrioventricular canal, Shone's syndrome, heterotaxy syndrome, double-outlet right ventricle, and isolated mitral or aortic atresia with a ventricular septal defect. Seven patients had a hospital length of stay of more than 2.5 months after the stage I palliation, 


\author{
Abbreviations and Acronyms \\ $\mathrm{BDG}=$ bidirectional Glenn \\ HLHS = hypoplastic left heart syndrome
}

5 of whom did not leave the hospital. When compared with the rest of the group, these 7 patients were outliers and expected to have a difficult postoperative course after BDG. They were excluded from further analysis. In addition, patients who died within 30 days of BDG were excluded.

A total of 92 patients were included in the initial cohort, all of whom were discharged after both their stage I and BDG palliations. These patients were deemed to comprise a standard risk group, which could provide the most pertinent insight into why unexpected attrition occurs after BDG. As of November 2010, these patients had undergone Fontan palliation or attrition (death or transplant) or were awaiting Fontan palliation (Figure 1). Seven patients are awaiting Fontan palliation and were removed from the risk factor analysis.

Analyzed data included patient demographics, cardiac anatomy, preBDG echocardiograms, pre-BDG cardiac catheterization, intraoperative variables, and postoperative hospital course. Routine use of antegrade cerebral perfusion for stage 1 palliation was initiated in May 2000, and this variable was included in the analysis as a surrogate for era. Traditional risk factors for interstage mortality between stage 1 and 2 palliation were included in the analysis. The primary outcome of interest was interstage attrition as defined by death or cardiac transplantation occurring after hospital discharge after BDG and before Fontan. The institutional review board of the Baylor College of Medicine approved this retrospective review of patient medical records.

All patients had a pre-BDG echocardiogram read by a pediatric cardiologist with expertise in imaging. The last pre-BDG echocardiogram report was included for analysis. Qualitative assessments of tricuspid and neoaortic valve regurgitation and of ventricular function were reported as none, trivial, mild, moderate, or severe. This analysis was repeated for all patients post-BDG echocardiograms performed before discharge.

All patients but 1 underwent pre-BDG cardiac catheterization at our institution. Hemodynamic data were retrospectively collected from catheterization reports. These data included saturations, pressures, calculated pulmonary vascular resistance, and Qp:Qs. Catheter-based interventions were recorded, including atrial septoplasty, aortic arch angioplasty, and aortic arch stenting.

All patients had operative reports available for analysis. Additional surgical interventions at the time of the BDG, including atrial septectomy, aortic arch repair, tricuspid valvuloplasty, and pulmonary artery repair, were recorded.

Data regarding postoperative hospital course after BDG were collected from the medical record. These data include length of intubation, hospital length of stay, and presence of a pleural effusion significant enough to require drainage by a new chest tube after removal of the initial operative chest tube.

Statistical analysis was performed using SPSS version 16.0 (SPSS Inc, Chicago, Ill). Univariate analysis was performed for demographic, preBDG echocardiogram, pre-BDG catheterization, and perioperative variables. Two-tailed Student $t$ test was used for continuous variables. Pearson chi-square or Fisher exact test was used for categoric variables. Survival graphs were constructed using Kaplan-Meier test. A population growth curve was constructed by taking patient weights at multiple times before BDG. Cox regression analysis was used to identify independent predictors of attrition. We performed a multivariable analysis by including variables in the Cox regression model that produced a significance value of less than 0.10 on univariate analysis.

\section{RESULTS}

The study cohort consisted of 92 patients (Figure 1). There were 8 deaths and 3 transplants before Fontan, yielding an interstage attrition rate of $12 \%$. Excluding the 7 patients awaiting Fontan increased the interstage attrition rate to $13 \%$. Interstage attrition occurred at a median of 391 days (range, 59-1175 days) after BDG. Seventy-three patients have undergone Fontan at a mean time of 3.4 years after BDG (range, 1.6-5.8 years). The family of 1 patient declined Fontan palliation because of significant neurologic injury. This patient underwent BDG approximately 8 years ago and is included in the risk factor analysis.

Patients who died during the interstage period are listed in Table 1, along with clinical characteristics and suspected causes of death. Six patients died with right ventricular dysfunction. Two patients died unexpectedly at home. One patient died of native aortic valve regurgitation leading to left ventricular dilation and right ventricular dysfunction. Three patients underwent cardiac transplantation for right ventricular dysfunction during the interstage period. The transplants occurred 245, 288, and 540 days after BDG. Two patients who died had cardiac anomalies beyond those normally associated with HLHS. One patient had a dysplastic native pulmonary valve, and one patient was born with a hypoplastic right lung and left pulmonary vein stenosis subsequently developed.

Analysis of demographic variables (Table 2) revealed no association between interstage attrition and the following variables: gender, anatomic subtype, use of antegrade cerebral perfusion, restrictive atrial septum at birth, age or weight at stage 1 palliation (surrogate for delayed presentation), stage 1 palliation operative characteristics, or age at BDG. Four patients had genetic syndromes, including Noonan syndrome, chromosome 6 and 17 translocation with minimal clinical sequelae, and 2 undiagnosed genetic syndromes. One of the patients with an undiagnosed genetic syndrome underwent heart transplantation 245 days after BDG. The small number of genetic conditions precluded further statistical analysis. All patients underwent stage 1 palliation with a systemic to pulmonary artery shunt; therefore, we could not analyze any differences between these shunts and right ventricle to pulmonary artery conduits. Only 3 patients were born prematurely. No patient required extracorporeal membrane oxygen after stage 1 palliation. The median length of stay after stage 1 palliation was longer for the patients who had interstage attrition (32 days; range, 17-66) than for those who did not (21 days; 9-62) $(P=.03)$. Weight at the time of BDG, whether expressed as an absolute number or as a $z$ score, was associated with interstage attrition (Table 2). Figure 2 demonstrates a tapering of the growth curve before BDG in the interstage attrition group. No patient required unplanned surgical intervention between stage 1 palliation and BDG.

Analysis of pre-BDG echocardiographic data (Table 3) revealed no association between right ventricular dysfunction or neoaortic regurgitation and interstage attrition. Moderate or severe tricuspid valve regurgitation was present on 


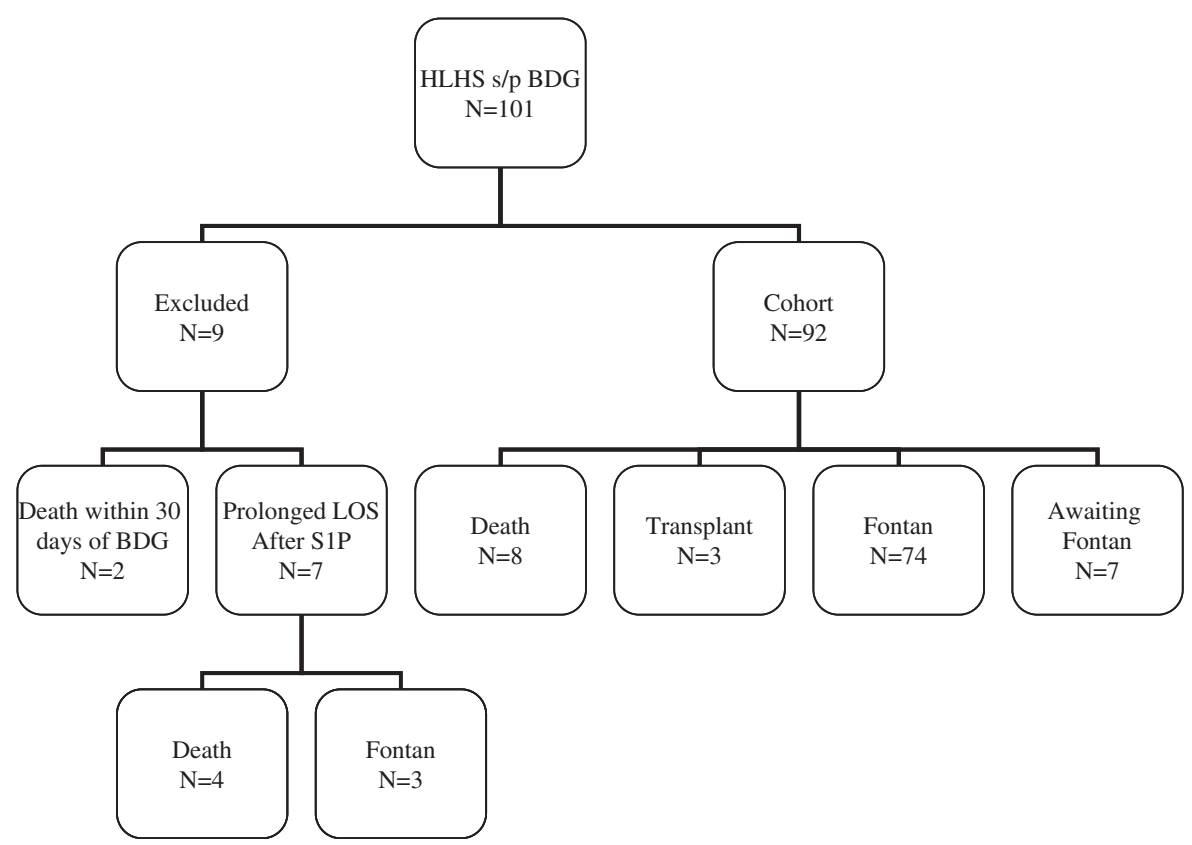

FIGURE 1. Outcomes of 101 patients who underwent BDG. BDG, Bidirectional Glenn; HLHS, hypoplastic left heart syndrome; LOS, length of stay; SIP, stage 1 palliation.

the pre-BDG echocardiogram in a significantly greater proportion of patients who did have interstage attrition $(55 \%)$ than in those who did not $(14 \%)(P<.01)$. A Kaplan-Meier survival curve (Figure 3) was constructed for patients dichotomized by the presence of moderate or severe tricuspid valve regurgitation before BDG.

Analysis of pre-BDG catheterization data (Table 3) revealed no statistically significant associations between any hemodynamic variables and interstage attrition. In addition, there was no association between any catheterization intervention and interstage attrition. Overall, the rate of transcatheter interventions was not different between groups.

Analysis of intraoperative procedures at BDG (Table 3) revealed that tricuspid valvuloplasty occurred more commonly in patients who had attrition $(27 \%)$ than in those

TABLE 1. List of patients who experienced death or cardiac transplantation between bidirectional Glenn and Fontan

\begin{tabular}{|c|c|c|c|c|c|c|c|c|}
\hline Patient & Anatomy & Comorbidities & $\begin{array}{c}\text { Hospital } \\
\text { LOS after } \\
\text { Norwood (d) }\end{array}$ & $\begin{array}{c}\text { Pre-BDG } \\
\text { RV function }\end{array}$ & $\begin{array}{c}\text { Pre-BDG } \\
\text { tricuspid } \\
\text { regurgitation }\end{array}$ & $\begin{array}{l}\text { Death or } \\
\text { transplant }\end{array}$ & $\begin{array}{c}\text { Months } \\
\text { after BDG }\end{array}$ & $\begin{array}{c}\text { Cause of death or } \\
\text { transplant }\end{array}$ \\
\hline 1 & AA, MS & None & 31 & Normal & Moderate & Death & 1.9 & RV dysfunction \\
\hline 2 & AS, MA & $\begin{array}{l}\text { Hypoplastic } \\
\text { right lung }\end{array}$ & 25 & Normal & Trivial & Death & 4.4 & Pulmonary vein stenosis \\
\hline 3 & AA, MS & $\begin{array}{l}\text { Dysplastic } \\
\text { pulmonary valve }\end{array}$ & 22 & Normal & Moderate & Death & 9.3 & $\begin{array}{l}\text { Neoaortic regurgitation, } \\
\text { RV dysfunction }\end{array}$ \\
\hline 4 & AA, MA & None & 65 & Normal & Moderate & Death & 12.8 & Sudden death \\
\hline 5 & AA, MA & None & 49 & $\begin{array}{l}\text { Depressed secondary } \\
\text { to recurrent coarctation }\end{array}$ & Severe & Death & 13.6 & RV dysfunction \\
\hline 6 & AA, MA & None & 35 & Moderately depressed & Moderate & Death & 22.7 & RV dysfunction, influenza A \\
\hline 7 & AA, MA & None & 36 & Normal & Trivial & Death & 29.0 & RV dysfunction \\
\hline 8 & AS, MS & None & 29 & Normal & Mild & Death & 38.5 & Sudden death \\
\hline 9 & AS, MS & None & 27 & Normal & Mild & Transplant & 8.0 & $\begin{array}{l}\text { RV dysfunction after cardiac } \\
\text { arrest after BDG }\end{array}$ \\
\hline 10 & AA, MA & None & 21 & Normal & Moderate & Transplant & 9.4 & $\begin{array}{l}\text { RV dysfunction, tricuspid } \\
\text { regurgitation }\end{array}$ \\
\hline 11 & AS, MS & None & 34 & Normal & Trivial & Transplant & 17.7 & $\begin{array}{l}\text { LV dilation, } \mathrm{RV} \text { dysfunction, } \\
\text { neoaortic regurgitation }\end{array}$ \\
\hline
\end{tabular}

Comorbidities, causes of death or transplant, and time to death or transplant after BDG are delineated. $L O S$, Length of stay; $L V$, left ventricular; $R V$, right ventricular; $A A$, aortic atresia; $A S$, aortic stenosis; $M A$, mitral atresia; $M S$, mitral stenosis. 
TABLE 2. Demographic variables of patients undergoing bidirectional Glenn

\begin{tabular}{lccc}
\hline \multicolumn{1}{c}{ Variable } & $\begin{array}{c}\text { Attrition } \\
(\mathbf{n}=\mathbf{1 1})\end{array}$ & $\begin{array}{c}\text { Alive } \\
(\mathbf{n}=\mathbf{7 4})\end{array}$ & $\begin{array}{c}\boldsymbol{P} \\
\text { value }\end{array}$ \\
\hline Anatomic subtype & & & .5 \\
AA/MA & $73 \%(8 / 11)$ & $57 \%(42 / 74)$ & \\
AA/MS & $0 \%(0 / 11)$ & $11 \%(8 / 74)$ & \\
AS/MA & $0 \%(0 / 11)$ & $7 \%(5 / 74)$ & \\
AS/MS & $27 \%(3 / 11)$ & $26 \%(19 / 74)$ & \\
Male gender & $64 \%(7 / 11)$ & $65 \%(48 / 74)$ & .94 \\
Restrictive atrial septum & $9 \%(1 / 11)$ & $19 \%(13 / 74)$ & .48 \\
$\quad$ at birth & $5.9 \pm 2.5$ & $7 \pm 4.7$ & .45 \\
Age at S1P (d) & $2.9 \pm 0.5$ & $3.1 \pm 0.5$ & .19 \\
Weight at S1P (kg) & $18 \%(2 / 11)$ & $36 \%(27 / 74)$ & .23 \\
Pre-ACP S1P & $181 \pm 40$ & $186 \pm 49$ & .8 \\
S1P CPB time (min) & $84 \pm 22$ & $77 \pm 22$ & .36 \\
S1P crossclamp time (min) & $27 \pm 17$ & $27 \pm 20$ & .92 \\
S1P DHCA time (min) & $23 \pm 10(\mathrm{n}=9)$ & $17 \pm 11(\mathrm{n}=47)$ & .15 \\
$\quad$ ACP era, min) & $32(17,66)$ & $21(9,62)$ & .03 \\
Median hospital length & & & \\
$\quad$ of stay after S1P (d) & $178 \pm 55$ & $202 \pm 66$ & .26 \\
Age at BDG (d) & $5.32 \pm 0.79$ & $6.16 \pm 1.02$ & .01 \\
Weight at BDG (kg) & $-2.26 \pm 0.68$ & $-1.74 \pm 0.79$ & .04 \\
Weight at BDG $(z$ score) & & & \\
\hline
\end{tabular}

Values expressed as mean \pm standard deviation, or median (range). $A A$, Aortic atresia; $A S$, aortic stenosis; $M A$, mitral atresia; $M S$, mitral stenosis; $S I P$, stage 1 palliation; $C P B$, cardiopulmonary bypass; $D H C A$, deep hypothermic circulatory arrest time; $A C P$, antegrade cerebral perfusion.

who did not $(5 \%)$, although this difference did not achieve statistical significance $(P=.06)$. Undergoing atrial septectomy, aortic arch repair, or pulmonary artery repair was not associated with interstage attrition.

Analysis of the postoperative hospital course data revealed that patients who had interstage attrition had longer intubation times (median 2 days vs 1 day, $P<.01$ ) and hospital length of stay (median 19 days vs 6 days, $P<.01$ ) after BDG than patients who did not. There was no statistically significant difference in postoperative pleural effusions between the groups $(18 \%$ vs $6 \%, P=.2)$.

We performed a multivariable analysis (Table 4) by including variables in the Cox regression model that produced a significance value of less than .10 on univariate analysis. The variables included in the analysis were post-stage I palliation hospital length of stay, weight $z$ score at BDG palliation, moderate or severe tricuspid valve regurgitation, and tricuspid valve repair. Multivariable analysis demonstrated that the presence of moderate or severe tricuspid valve regurgitation (hazard ratio, 6.02; 95\% confidence interval, $1.56-23.24 ; P<.01$ ) and weight $z$ score (hazard ratio, $0.38 ; 95 \%$ confidence interval, $0.16-0.88 ; P=.02$ ) were independent preoperative risk factors for interstage attrition.

We also investigated whether tricuspid valve repair in patients with moderate or severe tricuspid valve regurgitation was inversely associated with interstage attrition. There were 17 patients $(18 \%)$ with moderate or severe tricuspid

\section{Growth Curve of Infants with} HLHS Prior to BDG

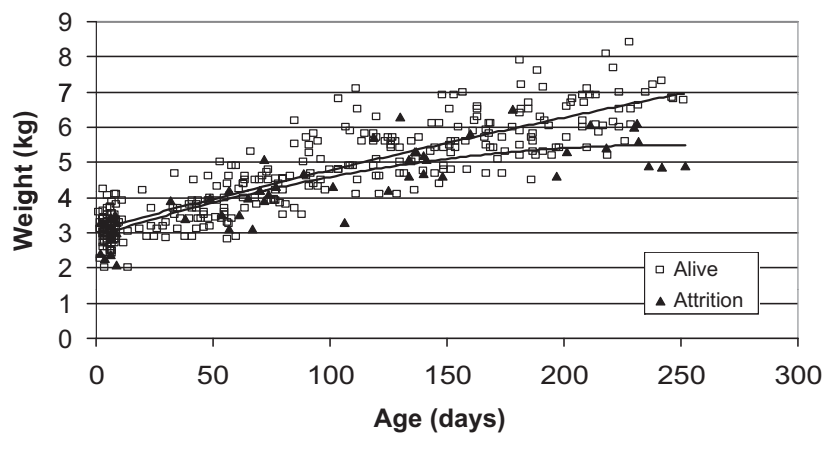

FIGURE 2. Growth curve before BDG. $B D G$, Bidirectional Glenn; $H L H S$, hypoplastic left heart syndrome.

valve regurgitation. Seven patients underwent valve repair with echocardiographic improvement of the regurgitation to mild or less noted. Of the 7 patients who underwent valve repair, 4 died. Of the 10 patients who did not undergo valve repair, 3 died. There was no difference in interstage attrition between these groups $(P=.26)$. Finally, 7 other patients had moderate or severe tricuspid valve regurgitation on echocardiography performed after BDG. Three of these patients had interstage attrition. Moderate or severe tricuspid valve regurgitation on echocardiography performed after BDG occurred more frequently in the attrition group, although this difference did not meet statistical significance $(27 \%$ vs $5 \%, P=.06$ ) (Table 3 ).

\section{DISCUSSION}

The objective of this study was to investigate risk factors for interstage attrition between BDG and Fontan palliation in children with HLHS. Our results demonstrate that moderate or severe tricuspid valve regurgitation and low weight $z$ score at the time of BDG are important risk factors for subsequent interstage attrition. Although right ventricular dysfunction was not associated with interstage attrition in our analysis, significant tricuspid valve regurgitation may result from and contribute to volume overload, which may have long-lasting effects on ventricular function. Traditional risk factors for interstage mortality between stage 1 and 2 palliation (genetic syndromes, prematurity, restrictive atrial septum at birth, age at stage 1 palliation, and need for extracorporeal membrane oxygen around stage 1 palliation) were not found to be risk factors for attrition after BDG or could not be evaluated because of insufficient numbers. The strengths of this study are in the large number of patients, exclusion of HLHS variants, and thorough analysis of risk factors at the time of BDG palliation.

Previous studies have produced conflicting results in regard to whether atrioventricular valve regurgitation is a risk factor for poor outcome after BDG. Ashburn and colleagues ${ }^{6}$ reported that repair of tricuspid valve regurgitation 
TABLE 3. Echocardiographic and catheterization data before bidirectional Glenn

\begin{tabular}{|c|c|c|c|}
\hline Variable & Attrition $(n=11)$ & Alive $(n=74)$ & $P$ value \\
\hline \multicolumn{4}{|l|}{ Echocardiographic (pre-BDG) } \\
\hline RV dysfunction (moderate or more) & $9 \%(1 / 11)$ & $12 \%(9 / 74)$ & 1.0 \\
\hline Tricuspid regurgitation (moderate or more) & $55 \%(6 / 11)$ & $14 \%(10 / 74)$ & $<.01$ \\
\hline Neoaortic valve regurgitation (more than mild) & $0 \%(0 / 11)$ & $2 \%(2 / 74)$ & 1.0 \\
\hline \multicolumn{4}{|l|}{ Catheterization } \\
\hline Right ventricular end-diastolic pressure ( $\mathrm{mm} \mathrm{Hg}$ ) & $9.6 \pm 5.2$ & $8.4 \pm 2.1$ & .24 \\
\hline Pulmonary artery pressure $(\mathrm{mm} \mathrm{Hg})$ & $13.6 \pm 3.7$ & $13.4 \pm 3.4$ & .87 \\
\hline Pulmonary vascular resistance (Wood units) & $1.4 \pm 0.6$ & $1.8 \pm 0.9$ & .12 \\
\hline Qp:Qs & $1.5 \pm 0.5$ & $1.3 \pm 0.6$ & .35 \\
\hline Arteriovenous $\mathrm{O}_{2}$ difference $(\%)$ & $26 \pm 6$ & $28 \pm 9$ & .37 \\
\hline Significant aortic arch obstruction & $18 \%(2 / 11)$ & $19 \%(14 / 74)$ & 1.0 \\
\hline Atrial septal gradient & $9 \%(1 / 11)$ & $18 \%(13 / 74)$ & 1.0 \\
\hline Aortic arch angioplasty & $9 \%(1 / 11)$ & $18 \%(13 / 74)$ & 1.0 \\
\hline Transcatheter intervention & $18 \%(2 / 11)$ & $27 \%(20 / 74)$ & .8 \\
\hline \multicolumn{4}{|l|}{ Intraoperative factors } \\
\hline Aortic arch repair & $18 \%(2 / 11)$ & $19 \%(14 / 74)$ & 1.0 \\
\hline Tricuspid valve repair & $27 \%(3 / 11)$ & $5 \%(4 / 74)$ & .06 \\
\hline Atrial septectomy & $18 \%(2 / 11)$ & $18 \%(13 / 74)$ & 1.0 \\
\hline Pulmonary artery repair & $27 \%(3 / 11)$ & $26 \%(19 / 74)$ & 1.0 \\
\hline \multicolumn{4}{|l|}{ Echocardiographic (post-BDG) } \\
\hline RV dysfunction (moderate or more) & $27 \%(3 / 11)$ & $11 \%(8 / 74)$ & .3 \\
\hline Tricuspid regurgitation (moderate or more) & $27 \%(3 / 11)$ & $5 \%(4 / 74)$ & .06 \\
\hline Neoaortic valve regurgitation (greater than mild) & $9 \%(1 / 11)$ & $2 \%(2 / 74)$ & 1.0 \\
\hline
\end{tabular}

Intraoperative factors at BDG and echocardiographic data after BDG. $Q p$, Pulmonary blood flow; $Q s$, systemic blood flow; $R V$, right ventricular.

at the time of BDG in patients with HLHS increased the risk of death after BDG. Likewise, in an analysis of risk factors for all single ventricles undergoing BDG, Scheurer and colleagues ${ }^{14}$ found that moderate or severe atrioventricular valve regurgitation predicted subsequent interstage attrition. In contrast with these findings, Mahle and colleagues ${ }^{15}$ reported that atrioventricular valve regurgitation did not affect survival in patients with a single ventricle undergoing BDG. A possible explanation for these discrepant results

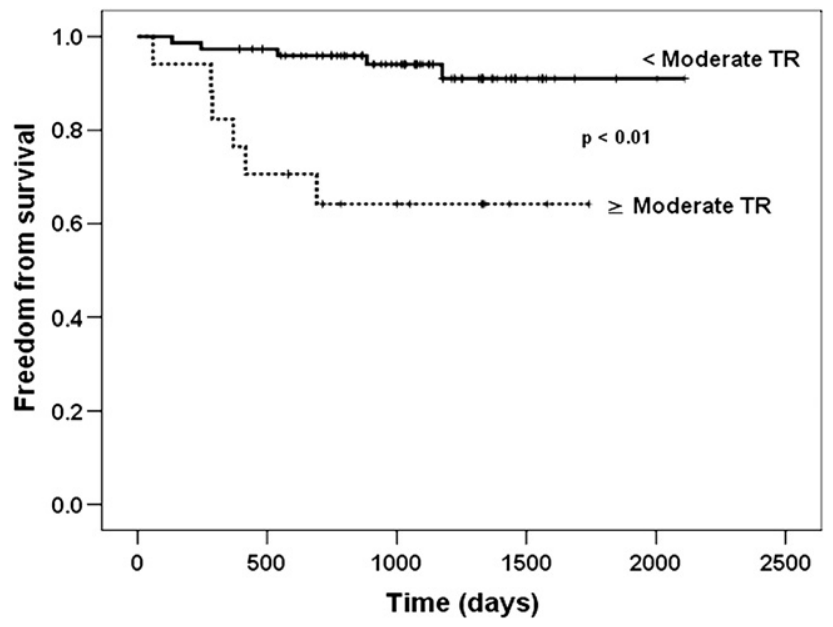

FIGURE 3. Kaplan-Meier survival curve dichotomized by the presence of moderate or severe tricuspid valve regurgitation before BDG. TR, Tricuspid regurgitation. is that the volume load created by significant atrioventricular valve regurgitation is more deleterious to the systemic right ventricle than to the systemic left ventricle. Previous studies disagree on the benefit of routine valvuloplasty at $\mathrm{BDG}$ in the setting of moderate or greater regurgitation. ${ }^{15,16}$ The number of patients undergoing valvuloplasty in our study was insufficient to draw any conclusion with regard to this controversy. Of note, we found a significant association between moderate or greater atrioventricular valve regurgitation on post-BDG echocardiography and interstage attrition.

Lower weight at time of BDG was found to be a risk factor for interstage attrition in our analysis. The weight gain demonstrated by the infants in our study corresponds well to previous reports. ${ }^{17,18} \mathrm{We}$ used weight $z$ scores to adjust for age at BDG. Anderson and colleagues ${ }^{19}$ demonstrated that low weight $z$ score at the time of BDG was associated with longer postoperative hospital length of stay. Poor

TABLE 4. Multivariable analysis of independent risk factors for interstage attrition after bidirectional Glenn $(n=85)$

\begin{tabular}{lccr}
\hline \multicolumn{1}{c}{ Variable } & HR & $\mathbf{9 5} \% \mathbf{C I}$ & $\begin{array}{c}\boldsymbol{P} \\
\text { value }\end{array}$ \\
\hline Tricuspid valve regurgitation & 6.02 & $1.56-23.24$ & $<.01$ \\
Tricuspid valve repair & 1.25 & $0.24-6.56$ & .79 \\
Median hospital length of stay after S1P (d) & 1.03 & $0.99-1.07$ & .21 \\
Weight at BDG ( $z$ score) & 0.38 & $0.16-0.88$ & .02 \\
\hline BDG $(\mathrm{n}=85) . H R$, Hazard ratio; $C I$, confidence interval; S1P, stage 1 palliation.
\end{tabular}


weight gain may be a marker of poor nutritional support, the degree of congestive heart failure, comorbidities, prolonged hospitalization, or poor cardiac function. It is unclear whether nutritional interventions, such as fortified feeds or gastrostomy tube placement, could improve weight gain before BDG or long-term outcomes. Our study also confirms the findings of Ghanayem and colleagues ${ }^{18} \mathrm{dem}-$ onstrating diminished growth velocity at approximately 4 to 6 months of age for infants with HLHS and thus suggesting that there may be no benefit of delaying the BDG procedure once a child attains a weight of $5 \mathrm{~kg}$. Furthermore, our findings raise the question of whether an early BDG may be indicated in patients who are not gaining weight appropriately. Individualizing the timing of BDG may be the most appropriate strategy.

This study has several limitations. First, follow-up duration is limited, and a small number of patients $(7 / 92,8 \%)$ were still awaiting Fontan palliation. Although we did exclude these patients from the risk factor analysis, any further death or transplant among this group of patients would increase the overall rate of attrition. All of our attrition occurred before 3 years post-BDG and all of our patients awaiting Fontan are at least 3.5 years post-BDG, suggesting that further attrition is unlikely. In prior studies, up to $40 \%$ of patients were still awaiting Fontan palliation. ${ }^{6,9,13}$ Our more complete follow-up may explain why our interstage attrition rate $(12 \%)$ seems higher than in prior studies $(6 \%-$ $9 \%){ }^{6,9,13}$ Our attrition rate between BDG and 12 months of age (3\% [3/92] in our analyzed cohort, $6 \%$ [6/101] before excluding patients) is similar to that reported by Ohye and colleague $^{20}$ in a recent large multi-institutional trial (6.3\% [25/397]). Second, because of insufficient numbers, certain traditional risk factors for interstage mortality between stage 1 palliation and BDG could not be effectively analyzed. Third, potentially important variables, including mode of feeding before BDG, right ventricular volumes on echocardiography, and postoperative pulmonary artery pressures after BDG, were unavailable for analysis. Finally, our cohort spans more than 10 years ending in 2007; therefore, attrition rates may not be representative of the current era.

\section{CONCLUSIONS}

Survival after BDG for HLHS infants is high. Although the causes of interstage attrition are varied, the majority of deaths and transplantations result from progressive ventricular dysfunction. Sudden unexpected death does occur in this population. Moderate or greater tricuspid valve regurgitation and low weight $z$ score at BDG are important risk factors for interstage attrition between the BDG and Fontan palliations. With improving survival after stage 1 palliation and during the first interstage period, an increasing number of candidates for BDG will likely be more marginal, with increased risk for subsequent interstage attrition.
Improvements in interstage outcomes after BDG may result from optimizing congestive heart failure therapies and nutritional support before BDG, goals of home-monitoring programs. Individualizing the timing of BDG palliation and addressing significant tricuspid valve regurgitation may also improve interstage outcomes after BDG.

\section{References}

1. Azakie T, Merklinger SL, McCrindle BW, Van Arsdell GS, Lee KJ, Benson LN, et al. Evolving strategies and improving outcomes of the modified Norwood procedure: a 10-year single-institution experience. Ann Thorac Surg. 2001;72: 1349-53.

2. Tweddell JS, Hoffman GM, Mussatto KA, Fedderly RT, Berger S, Jaquiss RD, et al. Improved survival of patients undergoing palliation of hypoplastic left heart syndrome: lessons learned from 115 consecutive patients. Circulation. 2002; 106:I-82-9.

3. Tibballs J, Kawahira Y, Carter BG, Donath S, Brizard C, Wilkinson J. Outcomes of surgical treatment of infants with hypoplastic left heart syndrome: an institutional experience 1983-2004. J Paediatr Child Health. 2007;43:746-51.

4. Mahle WT, Spray TL, Wernovsky G, Gaynor JW, Clark BJ 3rd. Survival after reconstructive surgery for hypoplastic left heart syndrome: a 15 -year experience from a single institution. Circulation. 2000;102:III-136-41.

5. McGuirk SP, Griselli M, Stumper OF, Rumball EM, Miller P, Dhillon R, et al. Staged surgical management of hypoplastic left heart syndrome: a single institution 12 year experience. Heart. 2006;92:364-70.

6. Ashburn DA, McCrindle BW, Tchervenkov CI, Jacobs ML, Lofland GK, Bove EL, et al. Outcomes after the Norwood operation in neonates with critical aortic stenosis or aortic valve atresia. J Thorac Cardiovasc Surg. 2003;125: 1070-82.

7. McHugh KE, Hillman DG, Gurka MJ, Gutgesell HP. Three-stage palliation of hypoplastic left heart syndrome in the university health system consortium. Congenit Heart Dis. 2010;5:8-15.

8. Gordon BM, Rodriguez S, Lee M, Chang RK. Decreasing number of deaths of infants with hypoplastic left heart syndrome. J Pediatr. 2008;153:354-8.

9. Pigula FA, Vida V, Del Nido P, Bacha E. Contemporary results and current strategies in the management of hypoplastic left heart syndrome. Semin Thorac Cardiovasc Surg. 2007;19:238-44.

10. Gaynor JW, Mahle WT, Cohen MI, Ittenbach RF, DeCampli WM, Steven JM, et al. Risk factors for mortality after the Norwood procedure. Eur J Cardiothorac Surg. 2002;22:82-9.

11. Simsic JM, Bradley SM, Stroud MR, Atz AM. Risk factors for interstage death after the Norwood procedure. Pediatr Cardiol. 2005;26:400-3.

12. Hehir DA, Dominguez TE, Ballweg JA, Ravishankar C, Marino BS, Bird GL, et al. Risk factors for interstage death after stage 1 reconstruction of hypoplastic left heart syndrome and variants. J Thorac Cardiovasc Surg. 2008;136:94-9.

13. Jacobs JP, O'Brien SM, Chai PJ, Morell VO, Lindberg HL, Quintessenza JA. Management of 239 patients with hypoplastic left heart syndrome and related malformations from 1993 to 2007. Ann Thorac Surg. 2008;85:1691-7.

14. Scheurer MA, Hill EG, Vasuki N, Maurer S, Graham EM, Bandisode V, et al. Survival after bidirectional cavopulmonary anastomosis: analysis of preoperative risk factors. J Thorac Cardiovasc Surg. 2007;134:82-9.

15. Mahle WT, Cohen MS, Spray TL, Rychik J. Atrioventricular valve regurgitation in patients with single ventricle: impact of the bidirectional cavopulmonary anastomosis. Ann Thorac Surg. 2001;72:831-5.

16. Reyes A 2nd, Bove EL, Mosca RS, Kulik TJ, Ludomirsky A. Tricuspid valve repair in children with hypoplastic left heart syndrome during staged surgical reconstruction. Circulation. 1997;96. II-341-3.

17. Davis D, Davis S, Cotman K, Worley S, Londrico D, Kenny D, et al. Feeding Difficulties and growth delay in children with hypoplastic left heart syndrome versus d-transposition of the great arteries. Pediatr Cardiol. 2008;29:328-33.

18. Ghanayem NS, Hoffman GM, Mussatto KA, Cava JR, Frommelt PC, Rudd NA, et al. Home surveillance program prevents interstage mortality after the Norwood procedure. J Thorac Cardiovasc Surg. 2003;126:1367-77.

19. Anderson JB, Border W, Lannon C, Uzark K, Khoury P, Beekman R. Poor interstage weight gain is common and adversely affects short-term outcome after the bi-directional Glenn shunt. J Am Coll Cardiol. 2008;51:A86.

20. Ohye RG, Sleeper LA, Mahony L, Newburger JW, Pearson GD, Lu M, et al. Comparison of shunt types in the Norwood procedure for single-ventricle lesions. N Engl J Med. 2010;362:1980-92. 